\title{
ANALISIS KANDUNGAN GARAM GUNUNG ASAL KRAYAN KABUPATEN NUNUKAN KALIMANTAN TIMUR
}

\author{
Herman, dan Rolan Rusli \\ Laboratorium Kimia Analisis Farmasi, Fakultas Farmasi Universitas Mulawarman Samarinda \\ Kalimantan Timur \\ email: herman.farmasi@yahoo.com
}

\begin{abstract}
Has been studied composition of mountain salt from Krayan, Nunukan, East Kalimantan. This study aims to determine the composition of the minerals contained in the mountain salt. Mountain salt is obtained from wells Krayan District residents were further prepared for analysis using a technique using Atomic Absorption Spectrometer (AAS), further by looking at the pattern of X-ray Diffraction (XRD) and Scanning electron microscopic (SEM). Based on the results obtained AAS has identified mineral deposits include: $\mathrm{Na}, \mathrm{K}, \mathrm{Mg}, \mathrm{Al}, \mathrm{Cu}, \mathrm{Zn}, \mathrm{Fe}$, $B a$, and Sr. From the results of XRD shows that the main peak of the salt Krayan shows major peaks for $\mathrm{NaCl}$ crystals with impurities such as $\mathrm{KCl}, \mathrm{CaCl}, \mathrm{MgCl}_{2}$, and $\mathrm{AlCl}_{3}$. SEM observation showed that morphology of Krayan salt have cube shape which is the shape of $\mathrm{NaCl}$ crystals with space group Fm3m and lattice parameter (a) $5.620 \AA$
\end{abstract}

Keywords : Mountain Salt, krayan, AAS, XRD, SEM

\begin{abstract}
Abstrak
Telah dilakukan penelitian analisis kandungan garam gunung asal Krayan Kabupaten Nunukan Kalimantan Timur. Penelitian ini bertujuan untuk mengetahui komposisi mineral yang terkandung dalam garam gunung. Garam gunung diperoleh dari sumur warga Kecamatan Krayan yang selanjutnya dipreparasi untuk dianalisis dengan menggunakan menggunakan teknik Spektrometer Serapan Atom (SSA), selanjutnya dengan melihat pola Difraksi Sinar X (XRD), dan Scanning Elektron Microscopy (SEM). Berdasarkan hasil SSA telah diidentifikasi diperoleh kandungan mineral antara lain: $\mathrm{Na}, \mathrm{K}, \mathrm{Mg}, \mathrm{Al}, \mathrm{Cu}, \mathrm{Zn}, \mathrm{Fe}, \mathrm{Ba}$, dan Sr. Dari hasil XRD terlihat bahwa puncak utama dari garam krayan tersebut menunjukkan puncak utama untuk Kristal $\mathrm{NaCl}$, dengan impurities antara lain $\mathrm{KCl}, \mathrm{CaCl}_{2}, \mathrm{MgCl}_{2}$, dan $\mathrm{AlCl}_{3}$. Selain itu hal ini didukung pula oleh pengamatan SEM, bahwa morfologi SEM garam krayan memperlihatkan bentuk kristal kubus yang merupakan bentuk dari Kristal $\mathrm{NaCl}$ dengan grup ruang $F m 3 m$ dengan panjang kisi kristal 5,620 .
\end{abstract}

Kata Kunci : Garam Gunung, Krayan, SSA, XRD,SEM

\section{PENDAHULUAN}

Garam gunung adalah garam yang berasal dari daerah pegunungan. Garam ini pada umumnya berasal dari sumber air yang memang berasa asin. Air garam sebenarnya merupakan air laut yang terjebak dalam struktur lapisan geologi tertentu pada jutaan tahun yang lalu waktu. Di Kalimantan Timur, garam jenis ini hanya terdapat di daerah Kabupaten Nunukan. Di dunia ini garam sejenis ini juga terdapat 
banyak di pegunungan Himalaya, namun penduduk di sekitar pegunungan Himalaya menggunakan garam ini sebagai obat kulit karena berasal dari magnesium dan kalsium.

Garam gunung yang terdapat di pedalaman Kabupaten Nunukan dimanfaatkan oleh masyarakat setempat sebagai bahan tambahan dalam makanan seperti sayur dan makanan yang lainnya sejak nenek moyang mereka sampai saat ini. Bagi masyarakat sekitar sumur garam, air dari sumur ini digunakan untuk memasak sayur/sajian berkuah. Selain digunakan dalam bahan makanan, garam gunung juga dipercaya dapat mengobati berbagai macam penyakit seperti kencing manis, darah tinggi, penyakit kulit dan beberapa penyakit lainnya. Garam gunung ini ada dua jenis, yaitu berbentuk bubuk seperi garam dapur pada umumnya dan berbentuk batangan, namun dalam cita rasa dan aroma yang sama. Garam ini diproses dengan cara yang sangat sederhana yaitu dengan cara memisahkan kadar air dan garamnya dengan cara air asin tersebut dimasak didalam wadah berupa kuali besar sampai airnya mengering dan hanya menyisakan bentuk bubuk-bubuk putih. Untuk pemprosesan garam yang berbentuk batangan, yaitu dengan cara air garam dimasukan ke dalam potongan-potongan bambu-bambu kecil, lalu dibakar sampai airnya mengering dan menyisakan gumpalan garam yang sudah mengeras yang berbentuk batangan kemudian garam batangan ini dikeluarkan dari bambu lalu dikemas dalam bungkusan daun.

Berdasarkan hasil wawancara dengan masyarakat setempat bahwa sayur yang menggunakan garam gunung berbeda dengan menggunakan garam yang dijual dipasaran, baik dari segi rasa maupun dari segi ketahanan. Bahkan garam gunung diyakini banyak mengandung yodium karena tidak ditemukannya masyarakat yang mengidap penyakit kekurangan yodium (gondok)

Garam adalah salah satu zat aditif pada bahan makanan yang ditambahkan untuk meningkatkan nilai gizi dan menambah cita rasa bahan makanan tersebut. Garam dapur yang baik adalah garam dapur yang memiliki Iodium pada garam tersebut. Syarat mutu Garam konsumsi beryodium yang baik berdasarkan SNI 3556:2010 disajikan pada Tabel 1.

Kajian ilmiah mengenai kandungan garam krayan tersebut belum dilaporkan. Oleh karena itu, maka dalam penelitian ini akan dilakukan "Analisis Kandungan Garam Gunung Asal Krayan Kabupaten Nunukan Kalimantan Timur".

Tabel 1. Syarat mutu Garam konsumsi beryodium

\begin{tabular}{|c|c|c|c|}
\hline No. & Kriteria & Satuan & Persyaratan \\
\hline 1. & Kadar air $\left(\mathrm{H}_{2} \mathrm{O}\right)(\mathrm{b} / \mathrm{b})$ & $\%$ & maks. 7 \\
\hline 2. & Kadar $\mathrm{NaCl}$ (natrium klorida) dihitung dari jumlah klorida (Cl-) (b/b) adbk & $\%$ & $\min 94$ \\
\hline 3. & Bagian yang tidak larut dalam air (b/b) adbk & $\%$ & maks. 0,5 \\
\hline 4. & Yodium dihitung sebagai kalium iodat $\left(\mathrm{KIO}_{3}\right)$ adbk & $\mathrm{mg} / \mathrm{kg}$ & $\min .30$ \\
\hline 5 . & Cemaran logam: & & \\
\hline & $1 \mathrm{Kadmium}(\mathrm{Cd})$ & $\mathrm{mg} / \mathrm{kg}$ & maks. 0,5 \\
\hline & 2 Timbal $(\mathrm{Pb})$ & $\mathrm{mg} / \mathrm{kg}$ & maks. 10,0 \\
\hline & 3. Raksa (Hg) & $\mathrm{mg} / \mathrm{kg}$ & maks. 0,1 \\
\hline 6. & Cemaran Arsen (As) & $\mathrm{mg} / \mathrm{kg}$ & maks. 0,1 \\
\hline 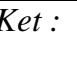 & $\begin{array}{ll}b / b & : \text { bobot/bobot } \\
\text { adbk } & : \text { atas dasar bahan kering }\end{array}$ & & \\
\hline
\end{tabular}




\section{METODE}

\section{Bahan}

Bahan yang digunakan adalah Garam Gunung asal Kecamatan Krayan, Kabupaten Nunukan Kalimantan Timur, yang diperoleh dari sumur warga yang berada di daerah pegunungan

\begin{abstract}
Alat
Alat yang digunakan dalam penelitian ini adalah seperangkat alat gelas yang biasa digunakan di laboratorium, seperangkat alat Spektrometer Serapan Atom (SSA), seperangkat alat XRD dan SEM.
\end{abstract}

\section{Prosedur Penelitian}

Prosedur penelitian ini, secara umum adalah Uji Komposisi Kimia Garam Gunung Asal Krayan Kabupten Nunukan dengan menggunakan teknik Spektrometer Serapan Atom (SSA), analisis struktur dan morfologinya dengan menggunakan XRD dan SEM.

\section{HASIL DAN PEMBAHASAN}

Secara umun kandungan mineral dalam tubuh memiliki fungsi yang esensial untuk mempertahankan kelangsungan hidup manusia. Kandungan dan fungsi beberapa mineral terlihat pada Tabel 2 .

Dari hasil pengujian dengan menggunakan SSA pada Tabel 3, terlihat bahwa konsentrasi unsur logam penyusun Garam Krayan adalah ion logan Natriun $(\mathrm{Na})$ yaitu sebesar 19,35\% atau 193.498 ppm. Garam yang mengandung ion natrium sangat baik bagi tubuh karena ion natrium berfungsi untuk mengatur osmolaritas cairan, $\mathrm{pH}$ dan volume darah, membantu transmisi rangsangan saraf dan kontraksi otot. Natrium termasuk golongan mineral makro (dibutuhkan >100 mg per hari). Angka kecukupan gizi (AKG) yang dianjurkan untuk dewasa berkisar antara $500-2400$ $\mathrm{mg}$. Dengan demikian untuk ion natrium garam krayan, telah memenuhi syarat untuk memenuhi nilai AKG dengan mengkonsumsi garam tersebut.

Tabel 2. Kandungan dan fungsi mineral

\begin{tabular}{|c|c|c|}
\hline Mineral Logam & Kegunaan & Jika Kekurangan \\
\hline Natrium (Na) & $\begin{array}{l}\text { Mempertahankan tekanan osmotik, } \\
\text { keseimbangan asam basa, meningkatkan tekanan } \\
\text { darah dan sumber ion tubuh }\end{array}$ & Penurunan tekanan darah \\
\hline Kalium (K) & $\begin{array}{l}\text { Menjaga tekanan osmotik, keseimbangan asam } \\
\text { basa, metabolism, sumber ion tubuh dan } \\
\text { aktifator enzim misalnya piruvat kinase }\end{array}$ & Gangguan metabolisme \\
\hline Kalsium (Ca) & $\begin{array}{l}\text { Pembentukan jaringan tulang/gigi, sumber ion } \\
\text { tubuh, transmisi impuls saraf, kontraksi otot, } \\
\text { penggumpalan darah, pengaturan permeabilitas } \\
\text { membrane sel, serta keaktifan enzim }\end{array}$ & $\begin{array}{l}\text { Pelunakan tulang (osteomalasia), } \\
\text { penurunan massa tulang (osteoporosis) }\end{array}$ \\
\hline Magnesium (Mg) & $\begin{array}{l}\text { Aktivator enzim peptidase dan enzim lain dan } \\
\text { meningkatkan tekanan osmotik }\end{array}$ & $\begin{array}{l}\text { Hypomagnesema (denyut jantung tidak } \\
\text { teratur, insomnia, lemah otot, kejang } \\
\text { kaki dan telapak kaki tangan gemetar }\end{array}$ \\
\hline Besi (Fe) & Pembentukan hemoglobin dan sel otot mioglobin & Anemia \\
\hline Seng $(\mathrm{Zn})$ & $\begin{array}{l}\text { Komponen enzim misalnya karbonat anhidrase } \\
\text { dalam sel darah merah, karboksi peptidase, } \\
\text { dehidrogenase dalam hati }\end{array}$ & $\begin{array}{l}\text { Gangguan metabolism, anak menjadi } \\
\text { kerdil dan ginjal hati membengkak }\end{array}$ \\
\hline
\end{tabular}


Tabel 3. Data Hasil Pengukuran AAS Garam Krayan

\begin{tabular}{llrr}
\hline \multirow{2}{*}{ No. } & \multicolumn{2}{c}{ Mineral logam } & \multicolumn{2}{c}{ Kadar } \\
\cline { 3 - 4 } & & $\mathbf{p p m}(\mathbf{m g} / \mathbf{k g})$ & $\mathbf{\%}(\mathbf{g} / \mathbf{g})$ \\
\hline 1. & Natrium $(\mathrm{Na})$ & 193498,00 & 19,3498 \\
2. & Kalium (K) & 2920,00 & 0,2920 \\
3. & Kalsium (Ca) & 3225,00 & 0,3225 \\
4. & Magnesium (Mg) & 1418,00 & 0,1418 \\
5. & Alumunium (Al) & 14,98 & 0,0015 \\
6. & Tembaga (Cu) & 0,99 & 0,0001 \\
7. & Seng (Zn) & 1,99 & 0,0002 \\
8. & Besi (Fe) & 59,92 & 0,0060 \\
9. & Barium (Ba) & 56,90 & 0,0060 \\
10. & Stronsium (Sr) & 497,00 & 0,0497 \\
11. & Belum diidentifikasi* & 798304,00 & 79,8304 \\
\hline
\end{tabular}

Ket : * Masih dalam tahapan pengidentifikasian

Jika dilihat kadungan kimia mineral lainnya, terdapat mineral logam berat, seperti logam tembaga, namun masih berada dibawah ambang batas, sehingga pemakaian garam Krayan pada bahan makanan masih relatif aman untuk dikonsumsi. Sedangkan berdasarkan hasil analisis pola XRD (Gambar 1) dari garam krayan tersebut terlihat adanya beberapa puncak utama. Puncak utama dan $d_{h k l}$ serta intensitas relatif dari difraksi sinar-X garam krayan ditampilkan pada Tabel 4.
Berdasarkan Tabel 4 terlihat bahwa puncak utama dari garam krayan tersebut menunjukkan puncak utama untuk Kristal $\mathrm{NaCl}$. Hal ini dapat dilihat dari data kristalografi standar untuk $\mathrm{NaCl}$ yang dikeluarkan oleh ICCD, dengan PDF No. 72-1668 (Gambar 2). Sedangkan untuk data kristalografi standard dari fasa impuritiesnya tidak ditampilkan. Secara lengkap interpretasi data hasil XRD garam krayan ditampilkan pada Tabel 5.

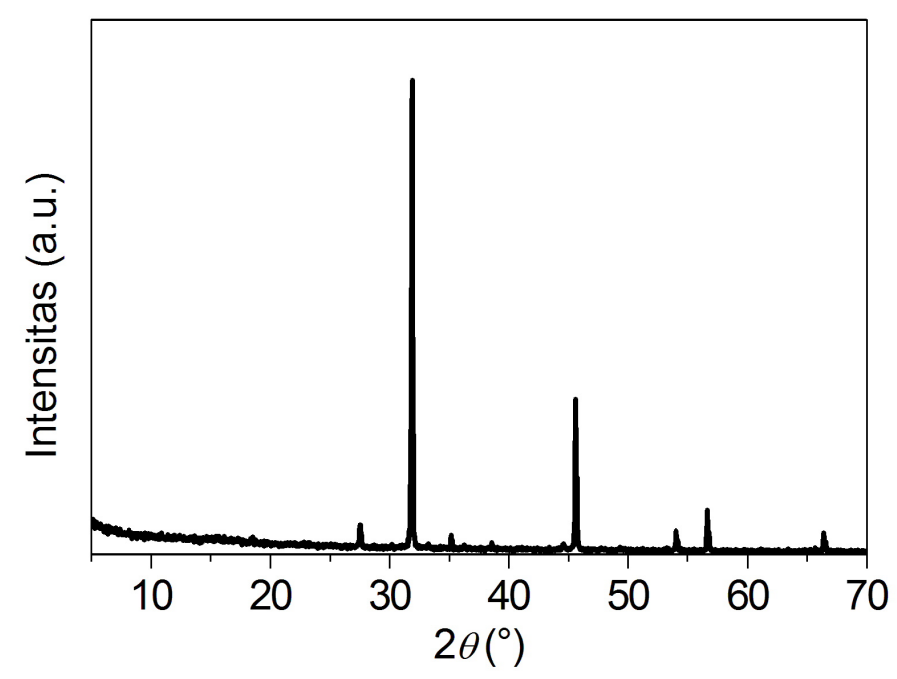

Gambar 1. Pola Difrakasi Sinar-X Serbuk Garam Krayan 
Analisis Kandungan Garam Gunung Asal Krayan Kabupaten Nunukan Kalimantan Timur

Tabel 4. Puncak Utama Difraksi Sinar-X Serbuk Garam Krayan

\begin{tabular}{lccc}
\hline No. & Posisi Puncak $2 \boldsymbol{\theta}\left({ }^{\circ}\right)$ & $\boldsymbol{d}_{\boldsymbol{h} \boldsymbol{l} \boldsymbol{l}}$ & Intensitas Relatif \\
\hline 1. & 27,511 & 3,23956 & 6,2 \\
2. & 31,8417 & 2,80814 & 100 \\
3. & 34,9831 & 2,56284 & 0,64 \\
4. & 36,2096 & 2,47879 & 0,84 \\
5. & 38,5974 & 2,33076 & 1,11 \\
6. & 44,4808 & 2,03517 & 1,25 \\
7. & 45,5814 & 1,98855 & 33,61 \\
8. & 49,4507 & 1,84163 & 0,36 \\
9. & 54,0231 & 1,69606 & 4,39 \\
10. & 56,5951 & 1,62493 & 11,04 \\
11. & 66,3783 & 1,40718 & 2,67 \\
\hline
\end{tabular}

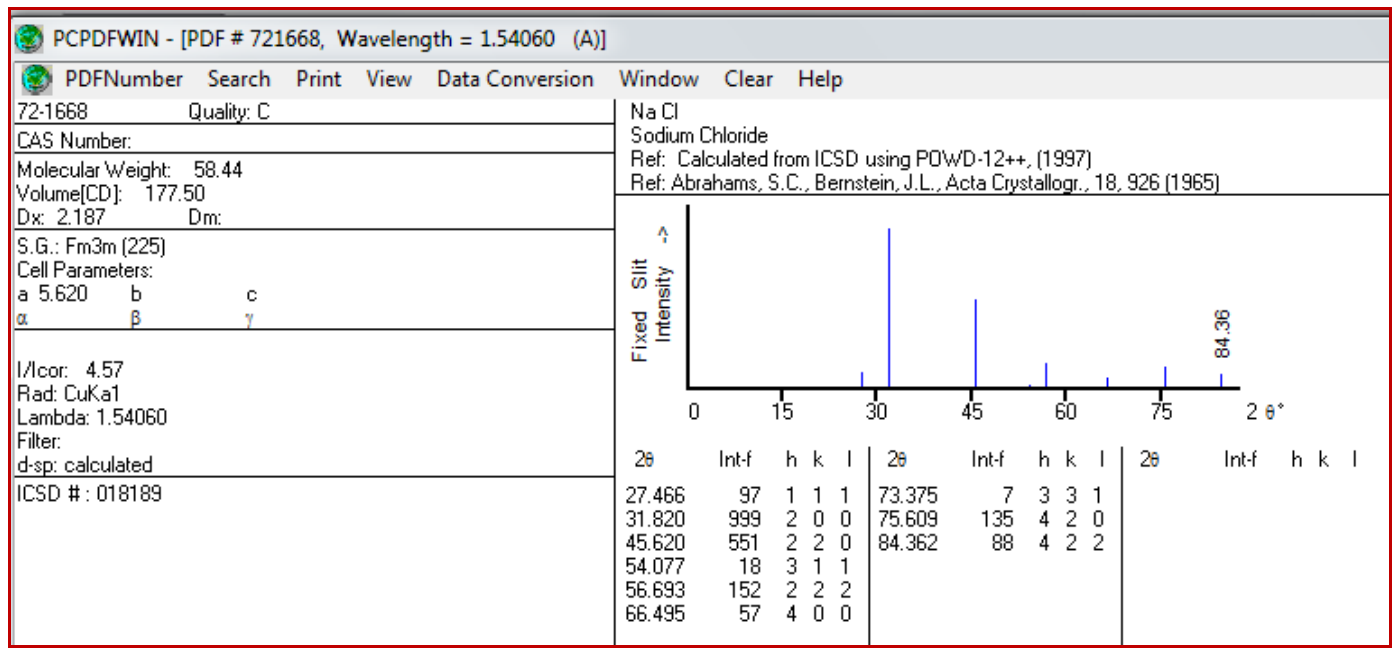

Gambar 2. Data Kristalografi NaCl PDF No. 72-1668

Tabel 5. Intepretasi Puncak Difraksi Sinar-X Serbuk Garam Krayan dibandingkan dengan Standar

\begin{tabular}{lccc}
\hline No. & Posisi Puncak $\mathbf{2 \theta}\left(^{\circ}\right)$ & Interpretasi Puncak dengan standar & No. Referensi standar (PDF No.) \\
\hline 1. & 27,511 & $\mathrm{NaCl}$ & $72-1668$ \\
2. & 31,8417 & $\mathrm{NaCl}$ & $72-1668$ \\
3. & 34,9831 & $\mathrm{KCl}$ & $77-2121$ \\
4. & 36,2096 & $\mathrm{AlCl}_{3}$ & $22-0010$ \\
5. & 38,5974 & $\mathrm{MgCl}_{2} \& \mathrm{CaCl}_{2}$ & $74-0521 \& 24-0223$ \\
6. & 44,4808 & $\mathrm{AlCl}_{3}$ & $22-0010$ \\
7. & 45,5814 & $\mathrm{NaCl}$ & $72-1668$ \\
8. & 49,4507 & $\mathrm{KCl}$ & $77-2121$ \\
9. & 54,0231 & $\mathrm{NaCl}$ & $72-1668$ \\
10. & 56,5951 & $\mathrm{NaCl}$ & $72-1668$ \\
11. & 66,3783 & $\mathrm{NaCl}$ & $72-1668$ \\
\hline
\end{tabular}

J. Trop. Pharm. Chem. 2012. Vol 1. No. 4. 


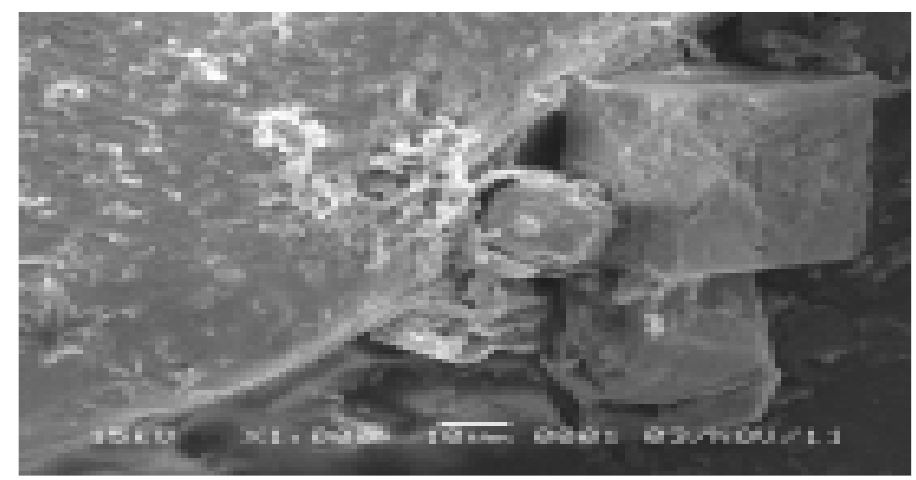

Gambar 3. Mikrograf SEM Garam Krayan

Dengan demikian dapat dikatakan bahwa garam krayan mengandung komposisi terbesar adalah senyawa $\mathrm{NaCl}$, dengan impurities antara lain $\mathrm{KCl}, \mathrm{CaCl}_{2}, \mathrm{MgCl}_{2}$, dan $\mathrm{AlCl}_{3}$. Hal ini sejalan dengan hasil yang diperoleh pada pengamatan AAS, yaitu komposisi terbesar dari garam krayan adalah ion logam Natrium $(\mathrm{Na})$.

Selain itu hal ini didukung pula oleh pengamatan SEM, dimana terlihat pada Gambar 3, bahwa morfologi SEM garam krayan memperlihatkan bentuk kristal kubus yang merupakan bentuk dari Kristal $\mathrm{NaCl}$. Kristal $\mathrm{NaCl}$ memiliki bentuk Kristal kubus dengan grup ruang $F m 3 m$ dan panjang kisi kristal 5,620 Å.

\section{KESIMPULAN}

Dari hasil penelitian yang telah dilakukan dapat disimpulkan sebagai berikut:

1. Berdasarkan hasil SSA telah diidentifikasi diperoleh kandungan mineral antara lain: $\mathrm{Na}, \mathrm{K}, \mathrm{Mg}, \mathrm{Al}, \mathrm{Cu}$, $\mathrm{Zn}, \mathrm{Fe}, \mathrm{Ba}$, dan Sr.
2. Dari hasil difraksi sinar $\mathrm{X}$ terlihat bahwa puncak utama dari garam krayan tersebut menunjukkan puncak utama untuk Kristal $\mathrm{NaCl}$, dengan impurities antara lain $\mathrm{KCl}, \mathrm{CaCl}_{2}$, $\mathrm{MgCl}_{2}$, dan $\mathrm{AlCl}_{3}$.

3. Dari hasil pengamatan SEM, bahwa morfologi SEM garam krayan memperlihatkan bentuk kristal kubus yang merupakan bentuk dari Kristal $\mathrm{NaCl}$ dengan grup ruang $F m 3 m$ dan panjang kisi kristal 5,620 ̊.

\section{DAFTAR PUSTAKA}

1. Badan Standardisasi Nasional, 2010. Garam Konsumsi Beryodium. SNI 3556:2010.

2. Association of Offical Analytical Chemistry. 2005. AOAC Official Method 999.11, Lead,Cadmium, Copper, Iron, and Zinc, 18th Edition, Chapter 9.1.09

3. Association of Offical Analytical Chemistry. 2005. AOAC Official Method 971.21 Mercury in Foods, Atomic Absorption Spectrophotometric method, Chapter 9.2.22

4. JCPDS-ICDD. 1998. PCPDFWIN. 